УДК 582.573.81:581.134.6

\title{
СОДЕРЖАНИЕ НЕКОТОРЫХ ГРУПП СОЕДИНЕНИЙ У HЕMEROCALLIS MINOR в УслОВИЯХ ИнтРОдУкциИ
}

\author{
() Л.Л. Седельникова", Т.А. Кукуикина \\ Центральный сибирский ботанический сад СО РАН, ул. Золотодолинская, \\ 101, Новосибирск, 630090 (Россия), e-mail: lusedelnikova@yandex.ru
}

В условиях лесостепной зоны Западной Сибири впервые установлено содержание сахаров, крахмала, сапонинов, аскорбиновой кислоты, пектинов, протопектинов, катехинов, дубильных веществ в надземных и подземных органах у Hemerocallis minor. Определено количественное содержание некоторых запасных и биологически активных веществ в листьях и корневищах.

Ключевые слова: запасные вещества, лист, корневище, красоднев малый, Сибирь.

\section{Введение}

Исследование биохимических особенностей растений природной флоры Сибири в условиях интродукции особенно актуально для рационального использования их в данном регионе. Среди дикорастущих растений недостаточно сведений о запасных веществах у видов из рода Hemerocallis L. (сем. Hemerocallidaceae). Во флоре Сибири произрастает Hemerocallis minor Mill. - Красоднев малый. Это - короткокорневищный многолетний поликарпик. Встречается на возвышенных, наиболее сухих песчаных участках долинных лугов, лесных и несколько остепненных лугах, в березово-сосновых лесах, среди кустарников в средней части Западной Сибири, на юге Восточной Сибири, Дальнем Востоке, в Северном, Северо-Восточном Китае, Монголии и на полуострове Корея. На западе произрастает до бассейна верховьев реки Оби. Некоторые виды имеют лекарственное и пищевое значение [1-2]. Из флавоноидов у Hemerocallis L. обнаружен кверцетин [3]. В условиях интродукции вегетативные органы растений адаптируются многофункционально, в том числе и на биохимическом уровне, что служит показателем их жизнедеятельности. Сведений о содержании метаболитов основных групп веществ в надземных и подземных органах у H. minor по литературным источникам не отмечено.

Цель работы - сравнительное изучениие содержания некоторых групп соединений в надземных и подземных органах Hemerocallis minor в условиях лесостепной зоны Западной Сибири.

\section{Экспериментальная часть}

Исследования проводили в Центральном сибирском ботаническом саду (ЦСБС) СО РАН в течение 2008-2011 гг. Опытные растения выращивали на интродукционном участке, расположенном в юговосточном районе Приобья Новосибирска. H. minor в коллекции лаборатории декоративных растений более тридцати лет. Образцы получены живыми особями из окрестностей села Огурцово Новосибирской области. Для количественного определения веществ (пектины, протопектины, катехины, сахара, крахмал, сапонины, дубильные вещества, аскорбиновая кислота) в надземных (лист) и подземных (корневище корневые шишки) органах. Использовали свежесобранное сырье. Пробы для анализа (навески 5-10 г) бра-

Седельникова Людмила Леонидовна - старший научный сотрудник, доктор биологических наук, тел.: (383) 339-97-94, e-mail: lusedelnikova @ yandex.ru Кукушкина Татьяна Абдулхаиловна - старший научный сотрудник, тел.: (383) 339-97-94, e-mail: lusedelnikova@yandex.ru ли в соответствии с фенофазами развития (весенняя вегетация, цветение, плодоношение) в течение вегетационного периода (май, июнь, сентябрь) до наступления устойчивых морозов.

\footnotetext{
* Автор, с которым следует вести переписку.
} 
Пектиновые вещества определяли карбазольным методом, основанном на получении специфического фиолетово-розового окрашивания уроновых кислот с карбазолом в сернокислой среде [4]. Определению пектиновых веществ мешало присутствие в образцах сахаров. Для их удаления измельченную навеску свежесобранного сырья заливали горячим этиловым спиртом (из расчета получения конечной концентрации спирта около 80\%), Далее экстрагировали на кипящей водяной бане в течение 20-30 мин. Экстракцию повторяли трижды. Остаток высушивали при небольшой температуре до отсутствия запаха спирта, экстрагировали водой для выделения растворимых пектинов, затем гидролизовали оставшиеся в навеске протопектины.

Количественное содержание сахаров определяли по методу А.С. Швецова и Э.Х. Лукьяненко [4]. Катехины определяли спектрофотометрическим методом, используя спиртовый экстракт, полученный при определении пектинов. Катехины (флаванолы) с 1\% ванилином в концентрированной соляной кислоте дают малиновое окрашивание [5]. Крахмал определяли методом кислотного гидролиза [6]. Гидролиз проводили соляной кислотой. Из полученного после гидролиза количества (\%) глюкозы вычитали сахара, выделенные ранее, и умножали на 0,9, так как одна весовая часть глюкозы соответствует 0,89996 весовых частей крахмала.

При анализе сапонинов измельченные образцы экстрагировали хлороформом в аппарате Сокслета для извлечения липидов, смол и др. Образцы высушивали и экстрагировали на водяной бане при $70{ }^{\circ} \mathrm{C} 30$ мин последовательно 50, 60 и 96\% этанолом. Количество сапонинов определяли весовым методом [7]. Дубильные вещества определяли перманганатометрическим методом. Экстракцию свежесобранного измельченного материала проводили водой на кипящей водяной бане в течение 50 мин [8].

Для определения аскорбиновой кислоты брали среднюю пробу (не менее 10 растений), чтобы в нее входили в соответствующих пропорциях все ткани каждой особи, растирали в ступке до гомогенного состояния в присутствии $1 \%$ раствора соляной кислоты. Затем добавляли $1 \%$ раствор щавелевой кислоты для стойкости аскорбиновой кислоты в экстракте. Количественное определение аскорбиновой кислоты проводили титрованием краской Тильманса. Для исключения веществ, реагирующих с 2,6дихлорфенолиндофенолом, проводили параллельный опыт. При нагревании с раствором сернокислой меди аскорбиновая кислота разрушается. Полученную поправку вычитали из данных титрования опытных экстрактов [4]. Кислотность (свободные кислоты) определяли путем титрования щелочью водного экстракта измельченного свежесобранного материала [9]. Все биохимические показатели, кроме аскорбиновой кислоты, рассчитаны на массу абсолютно сухого сырья. Определения проводили в трехкратной повторности.

Гидротермическому коэффициенту показатели по годам были: 2008 г. - теплый, умеренно увлажненный, 2009 г. - прохладный, избыточно увлажненный; 2010 г. - теплый, умеренно увлажненный; 2011 г. - слабо засушливый, с ранней теплой весной. Отрастание $H$. minor наступало в последней декаде апреля (2008, 2010-2011 гг.), первой-второй декадах мая (2009 г.). Развитие листовой поверхности проходило очень быстро. В третьей декаде мая отмечено начало бутонизации. Цветение наблюдали в первой декаде июня, с продолжительностью 20-30 дней. Полное отцветание отмечено во второй-третьей декадах июля. Начало плодоношения установлено в третьей декаде августа, конец - во второй декаде сентября. В августесентябре вегетативная масса имеет очень ярко выраженную зеленую окраску, которая сохраняется до осенних устойчивых заморозков. В природе $H$. minor достигает высоты до 50 см, с очень узкими листьями, малоцветковыми цветоносами 7-8 см в диаметре, с бледно-желтыми цветками, окрашенными снаружи в красновато-бурый цвет, особенно отчетливый на бутонах. В условиях агрофитоценоза его высота 70 90 см, диаметр цветка 10 см, их 10-12 шт. в соцветии. В клоне пятилетнего возраста формируется 15-20 генеративных побегов. Вид морозоустойчив и используется как декоративное растение в озеленении [10].

\section{Обсуждение результатов}

Анализ результатов исследования метаболитов основных групп веществ у H. minor в период весенней вегетации, цветения и плодоношения позволил установить индивидуальные и общие закономерности их накопления и расхода в надземных и подземных органах. Нами определено наличие восьми веществ в листьях и корневищах, из них семь идентичных. Количественное содержание для семи веществ приведено в таблицах 1, 2. Различие состояло в присутствии в подземных органах крахмала и отсутствии флавонолов и, наоборот, наличие последних в надземных органах и отсутствие первых. Установлено, что их содержание в органах $H$. minor изменяется как в течение одного вегетационного периода, так и по годам наблюдений и зависит от специфики выполняемых функций данных органов. Для сравнения рассмотрим обнаруженные соединения в подземных и надземных органах. 
Подземные органы. У H. minor в корневищах определены сахара, крахмал, аскорбиновая кислота, пектины, протопектины, катехины, сапонины, дубильные вещества. Отмечено, что содержание сахара в пределах вегетационного периода 2008 г. было относительно стабильное (4,2-5,8\%). Его количество уменьшалось в корневищах в 2 раза к периоду плодоношения (сентябрь) по сравнению с отрастанием в мае 2009-2010 гг. В 2008 г. показания сахара незначительно увеличивались к осени. Причем в слабозасушливый вегетационный период 2011 г. наличие сахара в подземных органах было в 2-3 раза меньше, по сравнению с умеренно и избыточно увлажненными 2009-2010 гг. (рис. 1а). Наименьшее количество сахара было 0,68\% в 2011 г. (20.05), далее возрастало до 3,60\% (24.06) и убывало до 2,30\% (20.09) по сравнению с предыдущими годами.

Установлено, что в корневищах к осени функционировало накопление крахмала, и его было в 6 раз больше, чем весной (рис. 2). Лишь в слабозасушливый 2011 г. он незначительно уменьшался. Такая же тенденция отмечена в наличии катехинов, пектинов и протопектинов, но их количество увеличивалось к осени в 2 раза (см. табл. 1). Однако определено, что содержание пектинов и протопектинов в подземных органах выше в период интенсивного весеннего отрастания особей H. minor. В корневищах наблюдали небольшое количество аскорбиновой кислоты, причем в умеренно и избыточно увлажненные годы (20082009 гг.) к осени оно увеличивалось в 2 раза, а в теплые и слабозасушливые 2010-2011 гг. уменьшалось. Во все годы наблюдений содержание катехинов увеличивалось в 2-10 раз и составляло 0,20-2,99 (сентябрь).

Выявлено, что накопление сапонинов происходило в период цветения и отцветания и увеличивалось к периоду перезимовки во все годы наблюдений, кроме слабозасушливого вегетационного периода 2011 г., где его было в 2-3 раза больше (рис. 3a). В корневищах не обнаружены флавонолы. Дубильные вещества увеличивались с мая по сентябрь и составляли от 1,92 до 4,79\%. Влажность корневищ имела от 57,8 до 73,4\%, их кислотность снижалась от 3,6 до 2,3\% к зимнему периоду покоя.

Таблица 1. Содержание некоторых групп соединений в подземных органах Hemerocallis minor (\% на абсолютно сухой вес) 2008-2011 гг.

\begin{tabular}{|c|c|c|c|c|}
\hline \multirow{2}{*}{ Месяц } & \multicolumn{4}{|c|}{ Год } \\
\hline & 2008 & 2009 & 2010 & 2011 \\
\hline \multicolumn{5}{|c|}{ Caxapa } \\
\hline Май & 4,17 & 8,72 & 6,54 & 0,68 \\
\hline Июнь & 5,84 & 3,83 & 6,48 & 3,60 \\
\hline Сентябрь & 5,75 & 4,12 & 3,43 & 2,30 \\
\hline \multicolumn{5}{|c|}{ Крахмал } \\
\hline Май & - & 9,03 & 2,35 & 44,85 \\
\hline Июнь & 3,12 & 13,34 & 21,58 & 43,78 \\
\hline Сентябрь & 18,32 & 23,66 & 41,22 & 30,51 \\
\hline \multicolumn{5}{|c|}{ Аскорбиновая кислота } \\
\hline Май & 10,74 & 11,57 & 20,65 & 34,97 \\
\hline Июнь & 15,85 & 7,83 & 11,94 & 11,44 \\
\hline Сентябрь & 22,74 & 21,48 & 8,28 & 16,25 \\
\hline \multicolumn{5}{|c|}{ Пектины } \\
\hline Май & - & 1,01 & 1,67 & 2,44 \\
\hline Июнь & 2,63 & 0,99 & 1,91 & 1,42 \\
\hline Сентябрь & 1,49 & 2,16 & 3,04 & 3,92 \\
\hline \multicolumn{5}{|c|}{ Протопектины } \\
\hline Май & 3,20 & 3,69 & 2,83 & 4,97 \\
\hline Июнь & 4,49 & 3,61 & 3,12 & 2,60 \\
\hline Сентябрь & 2,78 & 4,52 & 4,98 & 2,70 \\
\hline \multicolumn{5}{|c|}{ Катехины } \\
\hline Май & - & 0,11 & - & 0,18 \\
\hline Июнь & 0,24 & 0,12 & 0,14 & 0,07 \\
\hline Сентябрь & 2,99 & 0,20 & 0,32 & 2,10 \\
\hline \multicolumn{5}{|c|}{ Сапонины } \\
\hline Май & 3,35 & 0,40 & 16,93 & 19,80 \\
\hline Июнь & 13,57 & 10,97 & 5,02 & 61,11 \\
\hline Сентябрь & 19,48 & 8,93 & 17,26 & 47,52 \\
\hline
\end{tabular}


a)



б)

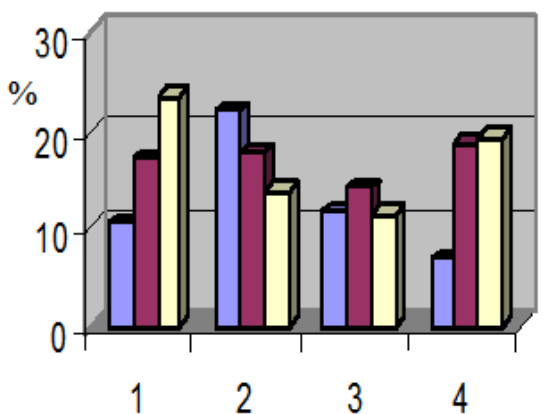

Рис. 1. Распределение сахара в подземных (а) и надземных (б) органах Hemerocallis minor. 1 - 2008 г., 2 - 2009 г., 3 - 2010 г., 4 - 2011 г.; ряд 1 - май, ряд 2 - июнь, ряд 3 - сентябрь

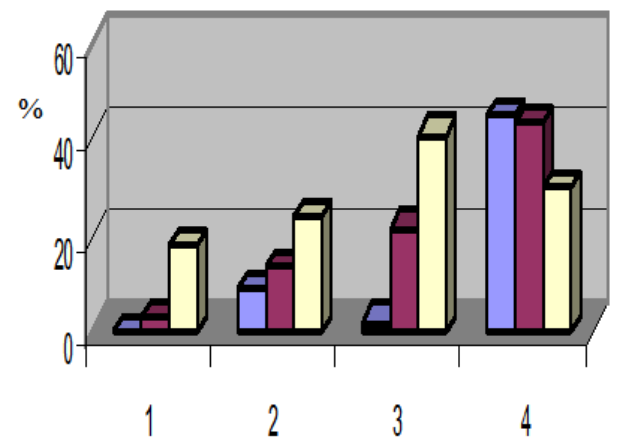

Рис. 2. Динамика изменения содержания крахмала в корневищах Hemerocallis minor 2008-2011 гг. (условные обозначения на рисунке 1).

Таблица 2. Содержание некоторых групп соединений в надземных органах Hemerocallis minor (\% на абсолютно сухой вес) (2008-2011 гг.)

\begin{tabular}{|c|c|c|c|c|}
\hline \multirow{2}{*}{ Месяц } & \multicolumn{4}{|c|}{ Год } \\
\hline & 2008 & 2009 & 2010 & 2011 \\
\hline \multicolumn{5}{|c|}{ Caxapa } \\
\hline Май & 10,40 & 21,98 & 11,64 & 6,96 \\
\hline Июнь & 17,03 & 17,79 & 14,02 & 18,64 \\
\hline Сентябрь & 23,29 & 13,78 & 11,47 & 19,15 \\
\hline \multicolumn{5}{|c|}{ Флавонолы } \\
\hline Май & 2,87 & 1,55 & 1,39 & 1,03 \\
\hline Июнь & 0,67 & 1,39 & 0,69 & 1,88 \\
\hline Сентябрь & 0,68 & - & 0,82 & 1,17 \\
\hline \multicolumn{5}{|c|}{ Аскорбиновая кислота мг\% } \\
\hline Май & 71,59 & 76,84 & 78,05 & 107,70 \\
\hline Июнь & 24,46 & 111,08 & 35,37 & 80,31 \\
\hline Сентябрь & 126,08 & 208,20 & 97,77 & 181,85 \\
\hline \multicolumn{5}{|c|}{ Пектины } \\
\hline Май & - & 0,26 & 1,03 & 0,71 \\
\hline Июнь & - & 0,24 & 0,30 & 0,65 \\
\hline Сентябрь & 1,28 & 1,35 & 0,40 & 0,67 \\
\hline \multicolumn{5}{|c|}{ Протопектины } \\
\hline Май & 3,76 & 2,95 & 3,95 & 3,57 \\
\hline Июнь & 4,11 & 2,38 & 2,72 & 4,16 \\
\hline Сентябрь & 2,27 & 3,75 & 2,59 & 3,39 \\
\hline \multicolumn{5}{|c|}{ Катехины } \\
\hline Май & 0,02 & 1,08 & 0,17 & 0,34 \\
\hline Июнь & 0,54 & 0,36 & 0,87 & 0,68 \\
\hline Сентябрь & 0,47 & 0,37 & 0,51 & 0,67 \\
\hline \multicolumn{5}{|c|}{ Сапонины } \\
\hline Май & 3,86 & 3,32 & 8,74 & 7,74 \\
\hline Июнь & 10,32 & 10,05 & 37,43 & 14,41 \\
\hline Сентябрь & 7,51 & - & 4,90 & 19,72 \\
\hline
\end{tabular}


a)

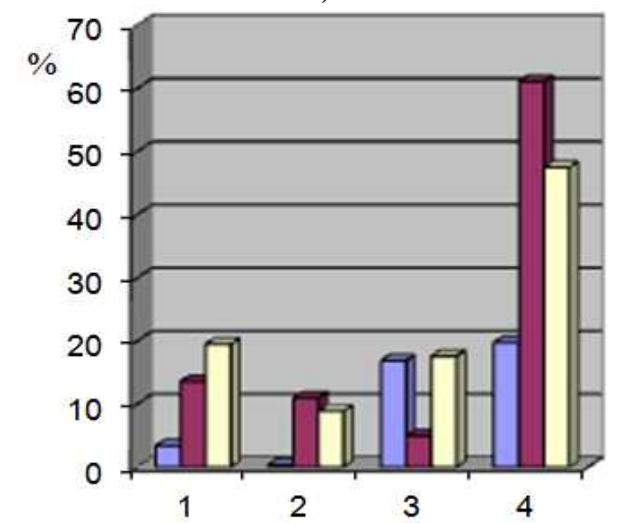

б)



Рис. 3. Распределение сапонинов в подземных (а) и надземных (б) органах Hemerocallis minor за 20082011 гг. (условные обозначения на рисунке 1).

Надземные органы. Определение компонентного состава в листьях позволило установить, что содержание сахара, сапонинов у них увеличивалось в 2 раза за период вегетации. Причем первого вещества отмечено в 3-5 раз больше в период осеннего плодоношения по сравнению с подземными органами (рис. 1б). В листьях H. minor обнаружены флавонолы и в весенний период роста и развития их было в 1,5-2 раза больше, чем в осенний (рис. 4).

Содержание пектинов и протопектинов в листьях отличалось изменчивостью в течение вегетационных периодов. Так, в прохладный избыточно увлажненный 2009 г. вышеуказанные компоненты возрастали, а в теплый умеренно увлажненный 2010 г. уменьшались в 1,5-2 раза. В слабозасушливый 2011 г. наличие пектинов было стабильное: 0,67-0,71\%, а протопектины к осени уменьшались незначительно (см. табл. $2)$. Дубильных веществ $(5,75 \%)$ и протопектинов $(3,76 \%)$ весной (20.05) было в 2 раза больше по сравнению с их содержанием в период осеннего предзимья (14.09).

Отмечено, что содержание аскорбиновой кислоты во все годы наблюдений к осени имели высокие показатели: 97,8-208,2 мг\%. Причем в листьях ее было в 5-10 раз больше, чем в корневищах. В листьях не обнаружено крахмала. Сравнительное содержание сапонинов в надземных и подземных органах $H$. minor, показало, что они накапливаются у последних в 1,5-2 раза больше (рис. 1а, б). Влажность листьев имела сравнительно стабильные показания и составляла во все годы наблюдений 66,97-82,53 \%, их кислотность была невысокая - 3,4-6,2\%.

Таким образом, в условиях Новосибирска (Приобская лесостепная климатическая провинция) впервые установлено количественное содержание в надземных и подземных органах H. minor сахаров, крахмала, сапонинов, аскорбиновой кислоты, пектинов, протопектинов, катехинов, дубильных веществ с ранней весны до поздней осени в течение четырех лет наблюдений. Очевидно, накопление и распределение крахмала в метаморфизированных органах, таких как корневище, играют существенную роль в морозоустойчивости зимующих геофитов. Поэтому высокое содержание крахмала, как нерастворимого полисахарида, в корневых шишках $H$. minor в осенний период способствует ускорению метаболических процессов и свидетельствует о способности успешной перезимовки в открытом грунте в суровых условиях лесостепной зоны Западной Сибири. Накопление основных метаболитов, таких как сапонинов, дубильных веществ, катехинов, крахмала, указывает на зимостойкость, патогеноустойчивость и декоративность, что выражено в высокой жизнедеятельности данного вида в условиях лесостепной зоны Западной Сибири.

Рис. 4. Динамика изменения содержания флавонолов в листьях Hemerocallis minor за 2008-2011 гг. (условные обозначения на рисунке 1).

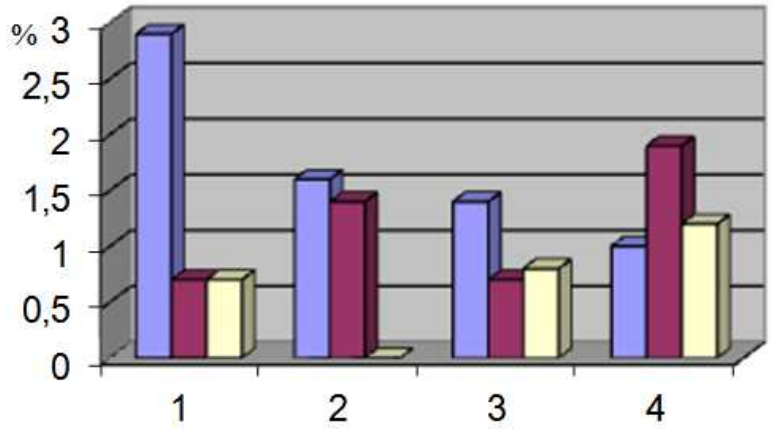


Стабильное содержание сахаров и витамина С в листьях, указывает на высокие адаптационные способности $H$. minor и возможность использования его при авитоминозах. Отмечена единая взаимосвязь распределения данных групп соединений в листьях и корневищах, которая обусловлена сезонным ростом и развитием H. minor, метеорологическими факторами вегетационных периодов.

\section{Bblвodbl}

1. Установлены индивидуальные и общие закономерности накопления и расхода запасных веществ в листьях и корневищах H. minor. Определено наличие семи общих групп соединений: сахаров, сапонинов, аскорбиновой кислоты, пектинов, протопектинов, катехинов, дубильных веществ.

2. Содержание сахара в надземных органах в 2 раза выше, чем в подземных, аскорбиновой кислоты в 8-10 раз соответственно.

3. Наличие сапонинов в подземных органах в 2-3 раза выше, чем в надземных, а увеличение содержания крахмала в предзимний период свидетельствует об адаптационной способности запасающих органов к зимнему относительному покою.

\section{Список литературы}

1. Полетико О.M. Hemerocallis L. - Красоднев, или Лилейник // Декоративные травянистые растения. Л., 1977. T. 2. C. $99-105$.

2. Конспект флоры Сибири: сосудистые растения. Новосибирск, 2005. 361 с.

3. Клышев Л.К., Бандюкова В.А., Алюкина Л.С. Флавоноиды растений. Алма-Ата, 1978. 219 с.

4. Методы биохимического исследования растений / под ред. А. Ермакова. Л., 1987. 430 с.

5. Кукушкина Т., Зыков А., Обухова Л. Манжетка обыкновенная (Alchmilla vulgaris L.) как источник лекарственных средств // Актуальные проблемы создания новых лекарственных препаратов природного происхождения. СПб., 2003. С. 64-69.

6. Бородова В., Горенков Э., Клюева О., Малофеева Л., Мегердичев Е. Методические указания по химикотехнологическому сортоиспытанию овощных, плодовых и ягодных культур для консервной промышленности. М., 1993. С. 64-65.

7. Киселева А., Волхонская Т., Киселев В. Биологически активные вещества лекарственных растений Южной Сибири. Новосибирск, 1991. 63 с.

8. Государственная фармакопея. М., $1968.816 \mathrm{c}$.

9. Кривенцов В. Методические рекомендации по анализу плодов на биохимический состав. Ялта, 1982. С. 7-9.

10. Седельникова Л.Л. Сибирский сортимент лилейников: состояние и перспективы // Сибирский вестник сельскохозяйственной науки. 2007. №7. С. 59-65. 
Sedelnikova L.L.", Kukushkina T.A. CONTENTS OF THE SOME GROUPS COMBINATIONS AT THE HEMEROCALLIS MINORIN CONDITIONS INTRODUCTION

Central Sibirian Botanical Garden SB RAS, RAS, Novosibirsk, Zolotodolinskaya str., 101 (Russia),

e-mail: lusedelnikova@yandex.ru

Development of ways and possibilities of adaptation of plants when introducing them in the forest-steppe zone of West Siberia is currently important and connected with biochemical processes, in particular, accumulation of storage substances in geophytes. Among them there are representatives of rhizomical plants of the genera Hemerocallis L. important in ornamental floriculture of our region.

The aim of the work - is comparative study of the component composition of storage substances in above the ground and organs Hemerocallis minor in the forest-steppe zone of West Siberia.

A quantitative composition of storage substances Hemerocallis was defined. Dynamics of accumulation of sugars, starch, saponins, ascorbic acid, pectins, protopectins, catechins and tanning matters in leafs and zhizomes in the forest-steppe zone of West Siberia was established for the first time. Pectins were determined by the carbazole method, sugars - by the A.S. Shvetsov and E. Kh. Lukyanenko method, catechins - by the spectrophotometric method, starch - by the acid hydrolysis method, saponins - by the weight method and tanning matters and acidity - by the titrometric method.

On the basis of the data obtained it was concluded:

1. Individual and common conformity of the accumulation and expenditure emergency substances in leafs and rhizomes were established. Eight common components of sugars, starch, saponins, ascorbic acid, pectins, protopectins, catechins and tanning matters were defined.

2. Content of sugars in above the ground organs by 2 times higher, than underground organs, accorbic acid by $8-10$ times higher, accordingly.

3. In underground organs of saponins by 2-3 times higher, than above the ground organs.

Keywords: storage substances, leaft, rhizome, Hemerocallis minor, Siberia.

\section{References}

1. Poletiko O.M. Dekorativnye travianistye rasteniia. [Ornamental grasses.]. Leningrad, 1977, vol. 2, pp. 99-105. (in Russ.).

2. Konspekt flory Sibiri: sosudistye rasteniia. [Synopsis Siberian flora: vascular plants]. Novosibirsk, 2005,361 p. (in Russ.).

3. Klyshev L.K., Bandiukova V.A., Aliukina L.S. Flavonoidy rastenii. [Flavonoids are plant.]. Alma-Ata, 1978, 219 p. (in Russ.).

4. Metody biokhimicheskogo issledovaniia rastenii. [Methods for biochemical study of plants]. Ed. A. Ermakov. Leningrad, 1987, 430 p. (in Russ.).

5. Kukushkina T., Zykov A., Obukhova L. Aktual'nye problemy sozdaniia novykh lekarstvennykh preparatov prirodnogo proiskhozhdeniia. [Actual problems of new drugs of natural origin.]. St. Petersburg, 2003, pp. 64-69. (in Russ.).

6. Borodova V., Gorenkov E., Kliueva O., Malofeeva L., Megerdichev E. Metodicheskie ukazaniia po khimikotekhnologicheskomu sortoispytaniiu ovoshchnykh, plodovykh i iagodnykh kul'tur dlia konservnoi promyshlennosti. [Methodological guidelines for Chemical Technology Variety Testing vegetable, fruit and berry crops for the canning industry.]. Moscow, 1993, pp. 64-65. (in Russ.).

7. Kiseleva A., Volkhonskaia T., Kiselev V. Biologicheski aktivnye veshchestva lekarstvennykh rastenii Iuzhnoi Sibiri. [Biologically active substances of medicinal plants of South Siberia.]. Novosibirsk, 1991, 63 p. (in Russ.).

8. Gosudarstvennaia farmakopeia. [State Pharmacopoeia.]. Moscow, 1968, 816 p. (in Russ.).

9. Kriventsov V. Metodicheskie rekomendatsii po analizu plodov na biokhimicheskii sostav. [Guidelines on the analysis on the biochemical composition of fruits.]. Yalta, 1982, pp. 7-9. (in Russ.).

10. Sedel'nikova L.L. Sibirskii vestnik sel'sko-khoziaistvennoi nauki, 2007, no. 7, pp. 59-65. (in Russ.).

Received May 24, 2013

\footnotetext{
* Corresponding author.
} 
